\title{
Analysis of Blood Aspiration Patterns during Pre-injection Tests of Injectable Fillers
}

\author{
Bong Cheol Kim, MD ${ }^{1}$ \\ Gi Woong Hong, MD, $\mathrm{PhD}^{2}$ \\ Seung Min Oh, MD, MMBA ${ }^{3}$ \\ Fang Wen Tseng, MD ${ }^{4}$ \\ ${ }^{1}$ Isu Lamar Clinic, Seoul, Korea \\ ${ }^{2}$ Samskin Plastic Surgery Clinic, Seoul, Korea \\ ${ }^{3}$ ON Clinic, Seoul, Korea \\ ${ }^{4}$ Milano Aesthetic Clinic, Taoyuan, Taiwan
}

Received March 26, 2020

Revised April 10, 2020

Accepted April 16, 2020

\author{
Correspondence \\ Fang Wen Tseng \\ Milano Aesthetic Clinic, Taoyuan 330, \\ Taiwan \\ E-mail: mosky21@yahoo.com.tw \\ https://orcid.org/0000-0001-7316-7395 \\ (C) Korean Society for Laser, Dermatology and Trichology \\ (c) This is an open access article distributed under \\ the terms of the Creative Commons Attribution Non- \\ Commercial License (http://creativecommons.org/ \\ licenses/by-nc/4.0) which permits unrestricted non- \\ commercial use, distribution, and reproduction in any \\ medium, provided the original work is properly cited.
}

\section{Background and Objectives}

Clinicians have yet to reach a consensus on whether blood aspiration tests are reliable when administering filler injections. Better understanding of the characteristics and patterns of blood aspiration tests for filler injections is important in reducing false negative results. In this study, we sought to outline the characteristics of blood aspiration tests for different types of fillers with different gauges of needles and cannulas.

\section{Materials and Methods}

Four biphasic hyaluronic acid fillers and ten monophasic hyaluronic acid fillers of four brands and two collagen stimulators were tested. Aspiration tests were performed with needles and cannulas of different gauges. The time before blood was seen in the needle hub and the vacuum space patterns generated were analyzed.

\section{Results}

Different aspiration patterns were observed with different fillers, depending on the viscosity of the product and the sizes of the needle and cannula used.

\section{Conclusion}

When factors influencing aspiration are considered, including the characteristics of fillers and the size of injection tools, aspiration tests with proper maneuver can be helpful to increase injection safety.

Key words

Fillers, Aspiration, Complications, Prevention

Supplementary video fille: This article contains supplementary material. 


\section{INTRODUCTION}

Filler procedures are commonly used to improve the signs of facial aging with minimal down-time [1]. Although filler injections carry a good safety profile, side effects do occur. Possible side effects of filler treatments include vascular, due to intravascular injection or compression, or nonvascular side effects. Vascular side effects may lead to serious tissue damage and warrant our attention [2].

During filler injections, many clinicians pull back the plunger to aspirate, in order to test whether a needle or cannula has penetrated and cannulated a blood vessel. However false negative aspirations observed clinically and in published studies remain to be overcome before this maneuver can be recommended as reliable and essential prior to filler injection [3].

Injectable fillers exhibit the properties of a viscous fluid $[4,5]$. During filler injections when the needle has been primed, the filler that fills the needle may prevent the influx of blood into the syringe upon aspiration. Studies have indicated that blood aspiration patterns during filler injections can vary depending on the filler characteristics and size of the needle or cannula used [6-9]. This lack of uniformity makes it difficult for researchers to recommend a standardized aspiration protocol which can be generalized to all different fillers.

The aim of this study is to describe the aspiration patterns displayed when individual filler products are used with different sizes of needles or cannulas, which may help in estimating the reliability of aspiration tests and reduce false negative results.

\section{MATERIALS AND METHODS}

\section{Injectable fillers}

To investigate aspiration patterns for filler injections, we tested both biphasic and monophasic hyaluronic acid (HA) fillers and collagen stimulators widely available in global and Korean markets. The biphasic HA fillers tested include Restylane ${ }^{\circledR}$ SubQ, Restylane ${ }^{\circledR}$ Lyft, Restylane ${ }^{\circledR}$ and Restylane ${ }^{\circledR}$ Skinbooster (Q-Med AB, Uppsala, Sweden). The monophasic HA fillers tested include Juvederm ${ }^{\circledR}$ Voluma, Juvederm ${ }^{\circledR}$ Volift and Juvederm ${ }^{\circledR}$ Volbella (Allergan, Irvine, CA, USA); Belotero ${ }^{\circledR}$ Volume, Belotero ${ }^{\circledR}$ Intense, Belotero ${ }^{\circledR}$ Balance and Belotero ${ }^{\circledR}$ Soft (Merz Pharma Gmbh, Frankfurt, Germany); and Neuramis ${ }^{\circledR}$ Volume, Neuramis ${ }^{\circledR}$ Deep and Neuramis ${ }^{\circledR}$ (Medytox, Seoul, South Korea). Collagen stimulators tested included Radiesse ${ }^{\circledR}$ (Merz Pharma Gmbh, Frankfurt, Germany) and Ellanse ${ }^{\circledR}$ M (Sinclair Pharma, London, UK), both diluted and undiluted. Different dilution ratios were tested with Radiesse ( $1.5 \mathrm{~mL}$ mixed with $0.26 \mathrm{~mL}, 0.5 \mathrm{~mL}$, or $1.5 \mathrm{~mL}$ of $2 \%$ lidocaine) and Ellanse $\mathrm{M}(1.1 \mathrm{~mL}$ mixed with 0.3 cc of $2 \%$ lidocaine) $[10,11]$.

\section{Aspiration test}

Human blood samples from volunteers were collected using a 23-G needle and stored in a blood collection tube (BD Vacutainer ${ }^{\circledR}, 8.5 \mathrm{~mL}$, Becton Dickinson, NJ, USA) containing citrate dextrose solution as anticoagulant. Each blood collection tube contained $8 \mathrm{~mL}$ of blood which was later poured into a stainless steel bowl just before the aspiration test.

Both needles and cannulas were tested with each filler products for aspiration, including the needle came within the package of each filler product, one additional needle larger in diameter, and two cannulas of frequently used sizes in clinical practice by the authors.

During the aspiration tests, the needles were primed with fillers expressed from and filled the needles or cannulas. The plunger of the syringe was then slowly pulled back to the end to generate negative pressure, until influx of blood was seen in the needle hubs or syringes, or until 15 seconds if no blood influx was observed. In positive tests, we recorded the time needed before an influx of blood was seen after applying negative pressure. To account for the loss of blood volume and the possibility of blood coagulation throughout multiple experiments, each experimental condition was evaluated using four tubes of blood.

Blood aspiration test results were categorized as rapidpositive (appearance of blood within $5 \mathrm{sec}$ ), late-positive (appearance of blood within 6-15 sec), or negative (no blood despite application of negative pressure for more than $16 \mathrm{sec}$ ).

\section{RESULTS}

Rapid-positive aspiration typically appeared as soon as the plunger was pulled back. Late-positive aspiration appeared later upon pulling the plunger all the way to the end and maintaining the negative pressure. We noted differences in aspiration results depending on the product, the diameter and length of the needle or cannula used. The results are summarized in Table 1.

\section{Hyaluronic acid fillers}

All four Restylane fillers showed rapid-positive results when using the needles enclosed in their respective packages. All four products were negative when a smaller caliber cannula was used and were positive when a larger caliber cannula was used. Among the positive cases with cannulas, 
Table 1. Results of blood aspiration tests

\begin{tabular}{|c|c|c|c|c|c|c|c|c|c|}
\hline & \multirow[b]{2}{*}{ Products } & \multicolumn{4}{|c|}{ Needle } & \multicolumn{4}{|c|}{ Cannula } \\
\hline & & Gauge* (length) & $\begin{array}{c}\text { Time }^{\dagger} \\
(\mathrm{sec})\end{array}$ & Gauge (length) & $\begin{array}{l}\text { Time } \\
\text { (sec) }\end{array}$ & Gauge (length) & $\begin{array}{l}\text { Time } \\
\text { (sec) }\end{array}$ & Gauge (length) & $\begin{array}{l}\text { Time } \\
\text { (sec) }\end{array}$ \\
\hline \multirow[t]{4}{*}{ Restylane $^{\circledR}$} & SubQ & $25 \mathrm{G}(16 \mathrm{~mm})$ & 2 & $23 \mathrm{G}(25 \mathrm{~mm})$ & 3 & $25 \mathrm{G}(40 \mathrm{~mm})$ & 35 & $22 \mathrm{G}(50 \mathrm{~mm})$ & 14 \\
\hline & Lyft & $29 \mathrm{G}(12 \mathrm{~mm})$ & 2 & $27 \mathrm{G}(13 \mathrm{~mm})$ & 1 & $25 \mathrm{G}(40 \mathrm{~mm})$ & 20 & $22 \mathrm{G}(50 \mathrm{~mm})$ & 5 \\
\hline & Restylane & $29 \mathrm{G}(12 \mathrm{~mm})$ & 2 & $30 \mathrm{G}(13 \mathrm{~mm})$ & 4 & $27 \mathrm{G}(50 \mathrm{~mm})$ & 16 & $25 \mathrm{G}(40 \mathrm{~mm})$ & 5 \\
\hline & Skinbooster & 29 G (12 mm) & 1 & $30 \mathrm{G}(13 \mathrm{~mm})$ & 2 & $27 \mathrm{G}(50 \mathrm{~mm})$ & 20 & $25 \mathrm{G}(40 \mathrm{~mm})$ & 5 \\
\hline \multirow[t]{4}{*}{ Belotero $^{\circledR}$} & Volume & 30 G (13 mm) & 20 & $27 \mathrm{G}(13 \mathrm{~mm})$ & 9 & $25 \mathrm{G}(40 \mathrm{~mm})$ & 15 & $22 \mathrm{G}(50 \mathrm{~mm})$ & 20 \\
\hline & Intense & $27 \mathrm{G}(13 \mathrm{~mm})$ & 6 & & & $25 \mathrm{G}(40 \mathrm{~mm})$ & 20 & $22 \mathrm{G}(50 \mathrm{~mm})$ & 25 \\
\hline & Balance & 30 G (13 mm) & 14 & $27 \mathrm{G}(13 \mathrm{~mm})$ & 4 & $25 \mathrm{G}(40 \mathrm{~mm})$ & 16 & $22 \mathrm{G}(50 \mathrm{~mm})$ & 15 \\
\hline & Soft & $30 \mathrm{G}(13 \mathrm{~mm})$ & 2 & & & $27 \mathrm{G}(50 \mathrm{~mm})$ & 8 & $25 \mathrm{G}(40 \mathrm{~mm})$ & 1 \\
\hline \multirow[t]{4}{*}{ Radiesse $^{\circledR}$} & No dilution & $27 \mathrm{G}(13 \mathrm{~mm})$ & 14 & $25 \mathrm{G}(16 \mathrm{~mm})$ & 20 & $25 \mathrm{G}(40 \mathrm{~mm})$ & 20 & $22 \mathrm{G}(50 \mathrm{~mm})$ & 25 \\
\hline & Dilution $^{\ddagger} 1(0.26 \mathrm{cc})$ & $27 \mathrm{G}(13 \mathrm{~mm})$ & 2 & $25 \mathrm{G}(16 \mathrm{~mm})$ & 1 & & & & \\
\hline & Dilution $^{\ddagger} 2$ (0.5 cc) & $27 \mathrm{G}(13 \mathrm{~mm})$ & 5 & & & $25 \mathrm{G}(40 \mathrm{~mm})$ & 15 & $22 \mathrm{G}(50 \mathrm{~mm})$ & 3 \\
\hline & Dilution $^{\ddagger} 3(1.5 \mathrm{cc})$ & $27 \mathrm{G}(13 \mathrm{~mm})$ & 1 & & & $25 \mathrm{G}(40 \mathrm{~mm})$ & 1 & & \\
\hline \multirow[t]{3}{*}{ Juvederm $^{\circledR}$} & Voluma & $27 \mathrm{G}(13 \mathrm{~mm})$ & 1 & & & $25 \mathrm{G}(40 \mathrm{~mm})$ & 14 & $22 \mathrm{G}(50 \mathrm{~mm})$ & 5 \\
\hline & Volift & $30 \mathrm{G}(13 \mathrm{~mm})$ & 2 & $27 \mathrm{G}(13 \mathrm{~mm})$ & 1 & $27 \mathrm{G}(50 \mathrm{~mm})$ & 14 & $25 \mathrm{G}(40 \mathrm{~mm})$ & 2 \\
\hline & Volbella & $30 \mathrm{G}(13 \mathrm{~mm})$ & 1 & & & $27 \mathrm{G}(50 \mathrm{~mm})$ & 5 & $25 \mathrm{G}(40 \mathrm{~mm})$ & 2 \\
\hline \multirow[t]{3}{*}{ Neuramis ${ }^{\circledR}$} & Volume & $27 \mathrm{G}(13 \mathrm{~mm})$ & 3 & $25 \mathrm{G}(16 \mathrm{~mm})$ & 5 & $25 \mathrm{G}(40 \mathrm{~mm})$ & 23 & $22 \mathrm{G}(50 \mathrm{~mm})$ & 23 \\
\hline & Deep & $27 \mathrm{G}(13 \mathrm{~mm})$ & 1 & $25 \mathrm{G}(16 \mathrm{~mm})$ & 2 & $27 \mathrm{G}(50 \mathrm{~mm})$ & 25 & $25 \mathrm{G}(40 \mathrm{~mm})$ & 13 \\
\hline & Neuramis & $30 \mathrm{G}(13 \mathrm{~mm})$ & 3 & $27 \mathrm{G}(13 \mathrm{~mm})$ & 1 & $27 \mathrm{G}(50 \mathrm{~mm})$ & 25 & $25 \mathrm{G}(40 \mathrm{~mm})$ & 5 \\
\hline \multirow[t]{2}{*}{ Ellanse ${ }^{\circledR} \mathrm{M}$} & No dilution & $27 \mathrm{G}(19 \mathrm{~mm})$ & 30 & $25 \mathrm{G}(16 \mathrm{~mm})$ & 30 & $25 \mathrm{G}(40 \mathrm{~mm})$ & 25 & $22 \mathrm{G}(50 \mathrm{~mm})$ & 30 \\
\hline & Dilution $^{\S}(0.3 \mathrm{cc})$ & $27 \mathrm{G}(19 \mathrm{~mm})$ & 7 & $25 \mathrm{G}(16 \mathrm{~mm})$ & 5 & $25 \mathrm{G}(40 \mathrm{~mm})$ & 14 & $22 \mathrm{G}(50 \mathrm{~mm})$ & 15 \\
\hline
\end{tabular}

Gauge*: pre-packaged needle enclosed with the filler product. Time ${ }^{\dagger}$ : time until blood was aspirated (seconds). Dilution ${ }^{\ddagger}$ : $0.26 \mathrm{cc}, 0.5 \mathrm{cc}$, and 1.5 cc of $2 \%$ lidocaine were mixed with Radiesse $1.5 \mathrm{~mL}$, using a female-to-female Luer-lok connector. Dilution $\$$ : 0.3 cc of $2 \%$ lidocaine was mixed with Ellanse M $1.1 \mathrm{~mL}$, using a female-to-female Luer-lok connector. Restylane ${ }^{\circledR}$, Belotero ${ }^{\circledR}$, Juvederm ${ }^{\circledR}$, and Neuramis ${ }^{\circledR}$ are manufactured with lidocaine. White box: rapid-positive (blood aspirated within 5 seconds), Yellow box: late-positive (blood aspirated within 6 to 15 seconds), Red box: negative (blood was not aspirated, even if negative pressure was applied for 16 seconds or longer), Gray box: no aspiration test performed.

three were rapid-positive and one was late-positive. Among the four Belotero fillers, only one showed rapid-positive aspiration using the needles in its package. Among all eight tests with the cannulas, only one resulted in rapid-positive aspiration. All three Juvederm fillers showed rapid-positive aspiration when using the needles in their respective packages, and all six tests with the cannulas were positive (four were rapid-positive and two were late-positive). The three Neuramis fillers also showed rapid-positive aspiration when using the needles supplied in their packages. However, only one of the six experiments with the cannulas were categorized as rapid-positive.

\section{Collagen stimulators}

In the four experiments using undiluted Radiesse, aspiration was negative in three and late-positive in one. When a 27-G needle was used, blood was aspirated at 14 seconds and observed along the syringe wall. When aspirating Radiesse diluted with $0.26 \mathrm{~mL}$ of lidocaine, we noted aspira- tion within 1-2 seconds (rapid-positive) for both needles. However, the blood was not seen along the inlet or wall of the syringe, but was faintly visible as a central column within the filler and was difficult to be observed. When the aspirated blood was discharged from the syringe, the blood was discharged without being mixed with Radiesse. Increasing the ratio of lidocaine in the mixture yielded more rapidpositive results in a similar aspiration pattern, and more blood appeared for easier observation. All tests with the needles and cannulas showed rapid-positive results when Radiesse was the most diluted (1:1 in volume) in this experiment.

All four aspiration tests for needles and cannulas loaded with undiluted Ellanse were negative. After diluting Ellanse with lidocaine $(0.3 \mathrm{cc})$, three were late-positive, and one was rapid-positive. Similar to the blood aspiration patterns for Radiesse and lidocaine dilutions, blood was faint and difficult to be observed. When the aspirated blood was discharged from the syringe, it was not mixed with Ellanse. 


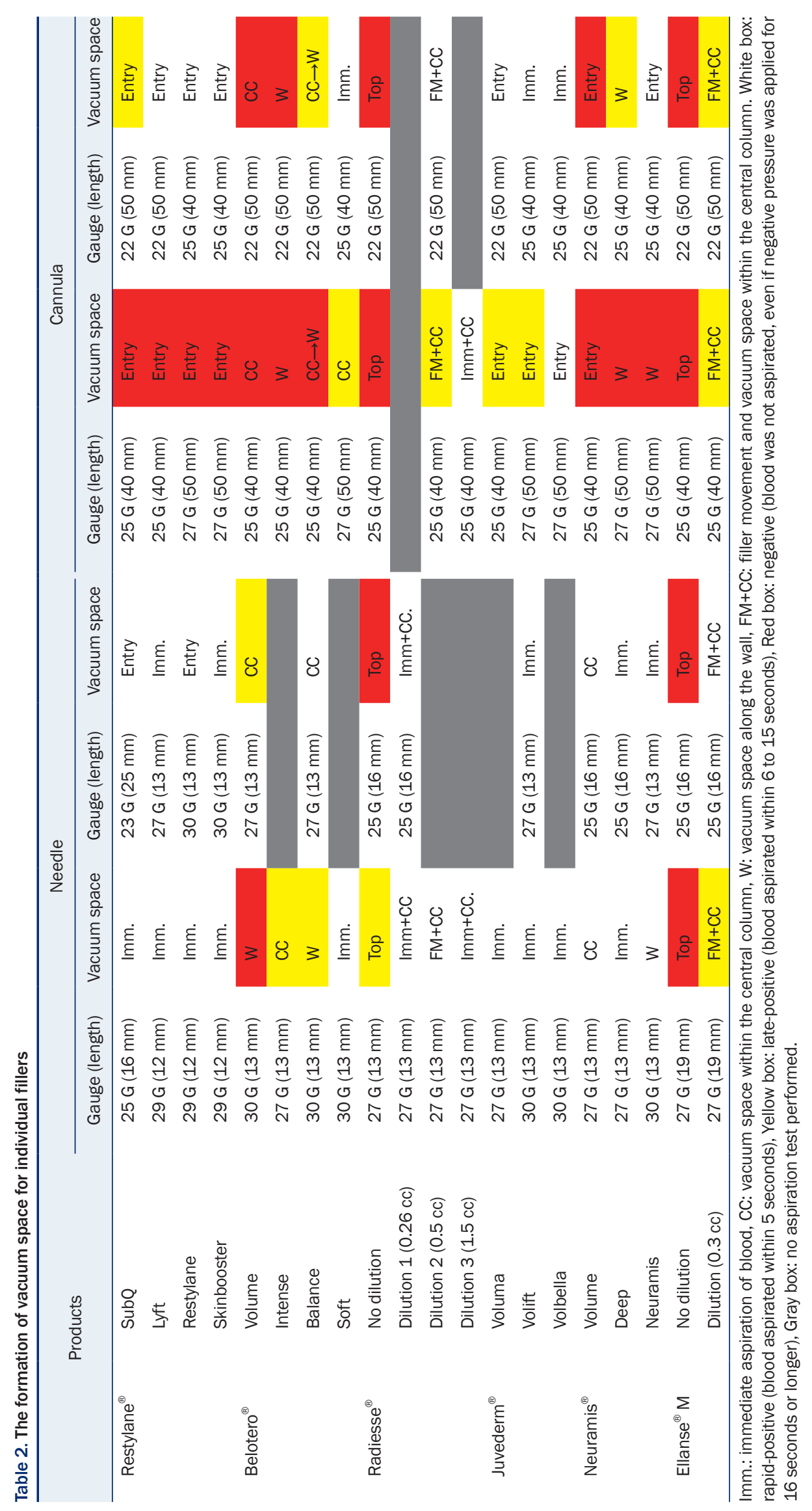




\section{AESTHETICS}

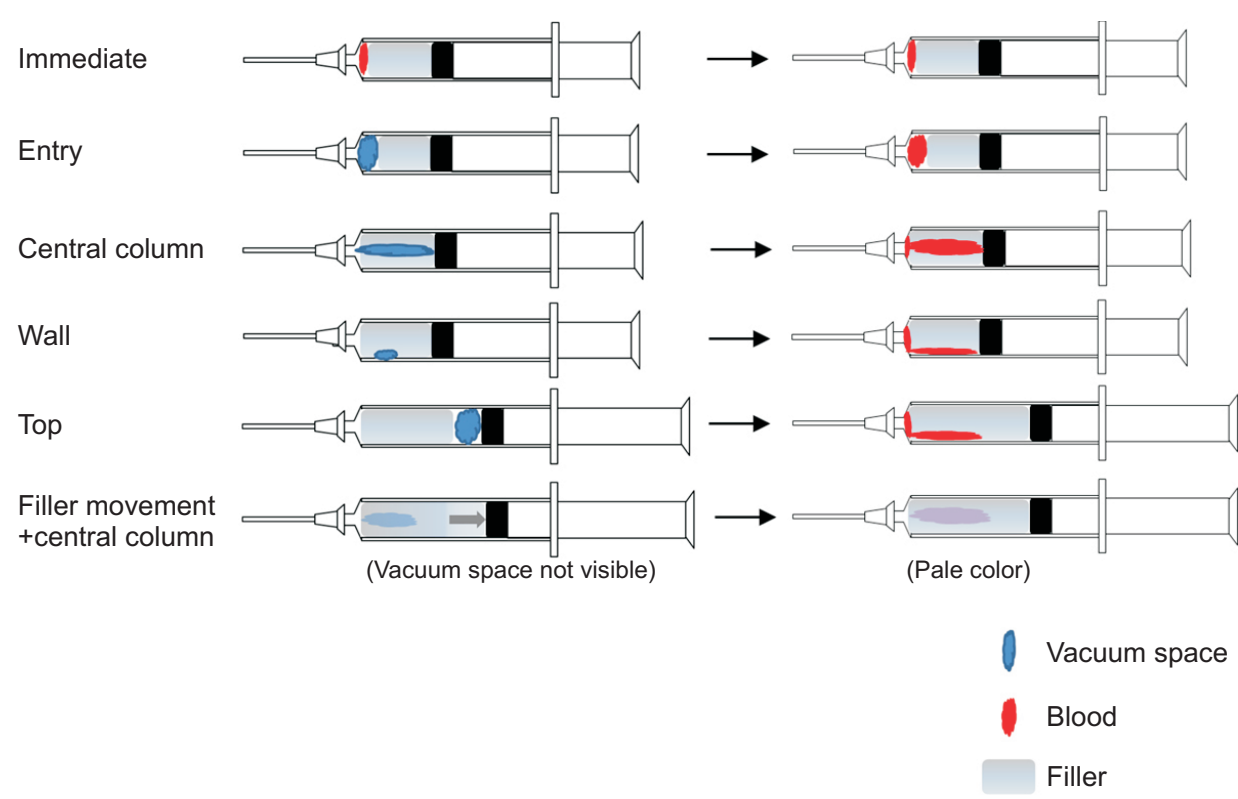

Fig. 1. Patterns of vacuum space and blood aspiration. Immediate: Aspiration of blood immediately after a small amount of vacuum space is formed. Entry: During aspiration, a vacuum space forms between the needle adaptor and the filler. This space is filled with blood. Central column: Upon retraction of the plunger, a columnar vacuum space is formed within the filler and fills with blood. Wall: Upon retraction of the plunger, a vacuum space is formed along the wall of the syringe and fills with blood. Top: A vacuum space is formed between the filler and the plunger upon retraction thereof. During aspiration, blood fills the entry space and the wall, while the filler fills the vacuum space. This pattern was observed only in experiments with undiluted collagen stimulator and mostly resulted in false negatives. Filler movement+ central column: Movement of filler toward the plunger upon retraction thereof. Aspirated blood is faintly observed within the filler. This pattern appeared only in experiments in which collagen stimulator was diluted with lidocaine, and most results were positive.

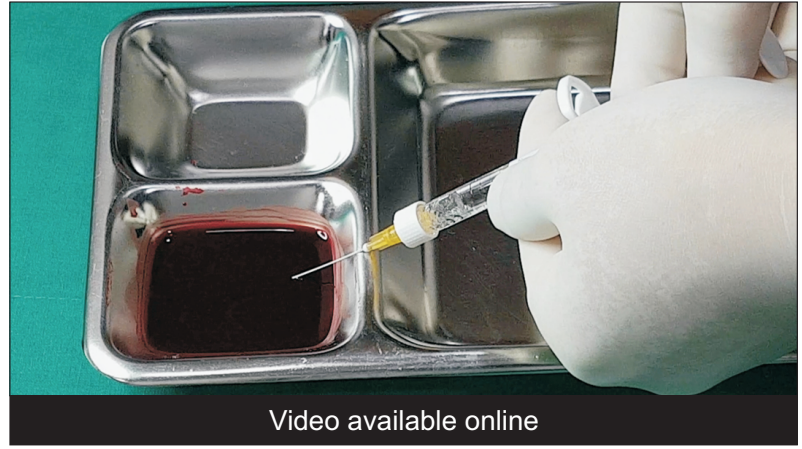

Supplementary video 1 . Supplemental Digital Content 1 demon맘물 strates entry pattern of vacuum space. The test was performed using Restylane/25 G cannula (40 mm) and blood was seen 5 seconds after aspiration. It is available at https://youtu.be/cD79rG6pJq8

\section{The formation of vacuum space}

With rapid-positive aspiration within 1 to $2 \mathrm{sec}$, an immediate influx of blood was observed as soon as a small amount of air was visible. With positive aspiration occurring later than $2 \mathrm{sec}$, various formations of vacuum space within the syringe were encountered. The formations of vacuum space were, however more commonly observed in negative aspiration tests. The patterns of vacuum space are depicted in Table 2 and Fig. 1.

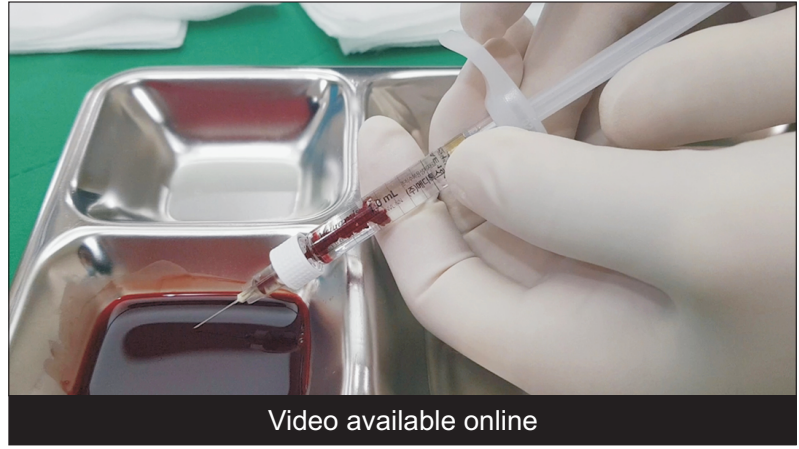

Supplementary video 2. Supplemental Digital Content 2 demonstrates central column pattern of vacuum space. The test was performed using Neuramis Volume/27 G needle $(13 \mathrm{~mm})$ and blood was seen 3 seconds after aspiration. It is available at https://youtu.be/_5219VR0n6l

With HA filler, vacuum space appeared as entry, central column, and wall patterns, in decreasing order of frequency (Supplementary video 1-3). For rapid-positive aspirations of HA fillers, the entry pattern of vacuum space was the most common; however, the entry pattern was also observed in some negative tests. The central column pattern was observed only for Belotero and Neuramis fillers.

The undiluted collagen stimulators showed mostly negative results and the top pattern, with a vacuum formed 


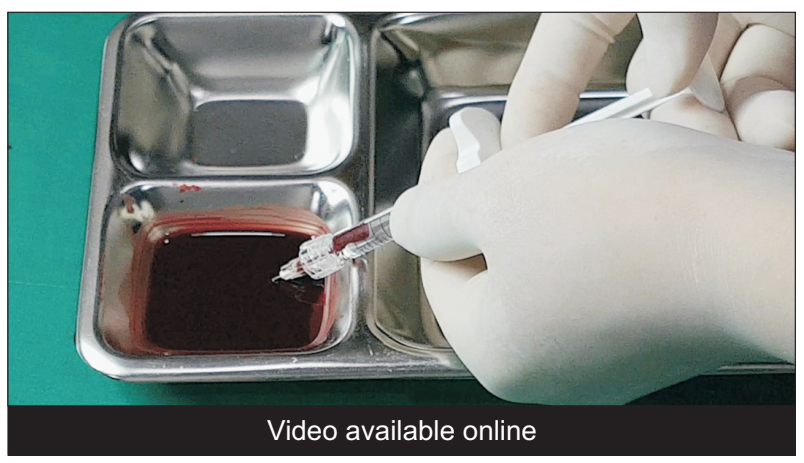

Supplementary video 3. Supplemental Digital Content 3 demon-

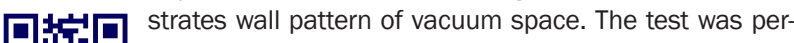

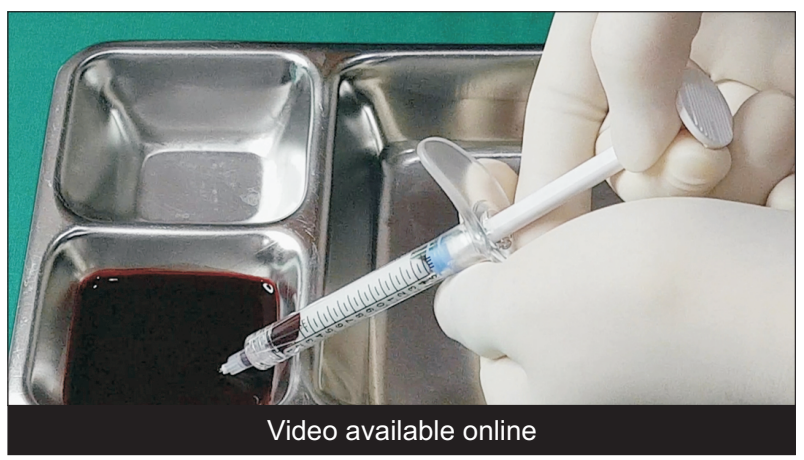

Supplementary video 4 . Supplemental Digital Content 4 demonan strates top pattern of vacuum space. The test was performed using Radiesse (Undiluted)/27 G needle (13 mm) and blood was seen 14 seconds after aspiration. It 口. is available at https://youtu.be/_RfWPeYj3EO

between the distal end of the filler and the plunger upon retraction, instead of forming a vacuum at the proximal end of the syringe, which prevented the influx of blood into the syringe (Supplementary video 4). While the collagen stimulators were diluted with lidocaine, rapid-positive and latepositive results were observed with faint blood aspiration in the center of the filler. Under the negative pressure created with retraction of the plunger, the central column of diluted collagen stimulator in the the syringe moved back toward the plunger, allowing an influx of blood to fill the empty space (Supplementary video 5).

\section{DISCUSSION}

Possible false negative aspirations raise suspicion of the reliability of this maneuver and hinder the establishment of a universal guideline to promote safety in filler injections $[3,6-9]$.

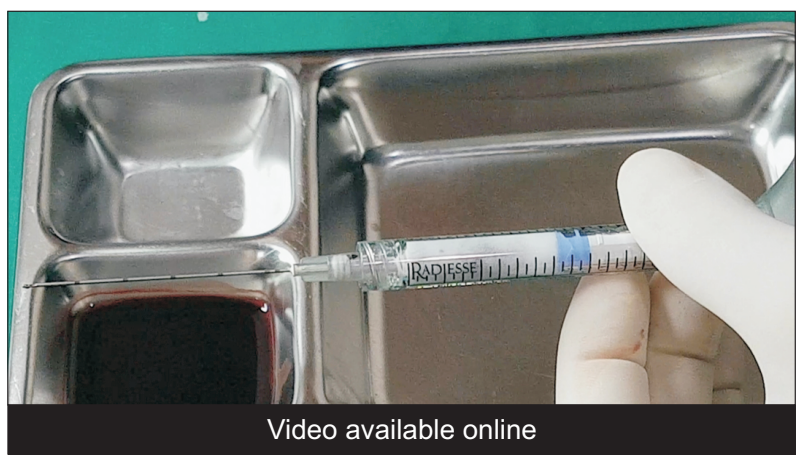

Supplementary video 5 . Supplemental Digital Content 5 demon口 1 strates filler movement+ central column pattern of vacuum space. The test was performed using Radiesse (diluted with $0.5 \mathrm{~mL}$ of lidocaine)/22 G cannula (50 mm) 回保骂: and blood was faintly visible as a central column within the filler 3 seconds after aspiration. It is available at https://youtu. be/uZLoGpETzN8

In this study, we found that aspiration test results differed depending on the characteristics of the filler and the size of needles or cannulas used. Restylane, Juvederm and Neuramis fillers produced consistent rapid-positive results with their respective needles in the package, supporting the reliability of aspiration tests to help avoid intravascular injection when using these products. Rapid-positive results were also observed with Belotero Balance/27 G needle and Belotero Soft $/ 30 \mathrm{G}$ needle, while Belotero Intense and Belotero Volume showed late-positive results ( 6 and $9 \mathrm{sec}$, respectively) with $27 \mathrm{G}$ needles. Aspiration time longer than $5 \mathrm{sec}$ exceeds common clinical practice and is considered less practical, suggesting that negative aspiration with the latter two products cannot be used alone to rule out the possibility of intravascular positioning of the needles, and other safer injection principles with needles must be followed such as slow injection with low pressure and delivering small amount of fillers with moving needles [12]. When cannulas were tested with HA fillers in the present study, most of the results were late-positive or negative, implying that aspiration with cannulas offers little if any help during HA filler injections.

Both undiluted Radiesse and Ellanse collagen stimulators showed mostly negative aspiration results, indicating that negative aspiration results cannot be used to rule out the intravascular positioning of the needles. However when 1.5 $\mathrm{mL}$ of Radiesse is diluted with at least $0.26 \mathrm{~mL}$ of lidocaine and when $1.1 \mathrm{~mL}$ of Ellanse is diluted with $0.3 \mathrm{~mL}$ of lidocaine, both mixtures exhibited positive aspirations. Lowering the viscosity of fillers through dilution may increase the reliability of aspiration tests clinically. One should carefully observe the aspiration process as the tinge of blood influx into diluted white collagen stimulators can appear pale and 
gray and difficult to be detected. Higher dilution ratio with increasing amounts of lidocaine decreased the opacity of the mixtures and allowed easier detection of the aspirated blood.

In addition to filler viscosity, factors influencing aspiration include the inner diameter (caliber) and the length of the needle or cannula [13]. In the present study, fillers that showed negative aspiration results with a smaller caliber needle/ cannula often had late-positive results when the same filler was tested with a larger caliber needle/ cannula. Similarly, fillers which showed late-positive results with smaller caliber needle/ cannula often had rapid-positive when aspiration was performed with a larger caliber needle/ cannula. These observations proved that compared with smaller gauge needles and cannulas, those with larger diameters aspirate more easily, with shorter time needed before an influx of blood can be seen upon aspiration, and may be more useful to increase the sensitivity of aspiration tests in daily practice.

Comparing the results of cannulas with needles for the same filler, cannulas had more negative results or required longer aspiration time before an influx of blood can be observed, even if the cannula gauges were larger than the needles. We believe this is because the longer lumens of cannulas exerted more friction between its inner wall and the fillers, and higher negative pressure is required for longer time to retract the fillers in the cannula back into the syringe before blood can be aspirated and observed.

We observed various patterns of vacuum space prior to the influx of blood, and those for collagen stimulators were different from those for HA fillers. All eight tests with undiluted Radiesse and Ellanse showed a top pattern, which was not observed in the tests with HA fillers. Among these eight tests of undiluted collagen stimulators that showed a top pattern of vacuum space, all but one were negative. The tests of diluted collagen stimulators showed a central column pattern of vacuum space in the syringe, the blood influx later took this space in the center of the syringe and was surrounded by opaque product.

In addition to the factors discussed above, a successful aspiration test also relies on proper techniques. The needle must be fixed in position during both aspiration and injection, ideally with the needle tip slightly touching the periosteum and the injector's non-dominant hand supporting the syringe. If the needle had been inadvertently moved, the aspiration test is meaningless. The retraction of the plunger should be as much backwards as possible to generate enough negative pressure, and hold for at least five seconds before determining a negative result and proceed on injection.

\section{CONCLUSION}

Aspiration results are influenced by the filler characteristics, the lumen diameter and length of the needles/ cannulas. Some fillers produce consistently positive aspiration results within seconds when used with proper-sized needles. Aspiration tests with these combinations can be helpful to avoid intravascular injections. Other more viscous fillers require higher negative pressure to be aspirated and clinicians should not rely solely on aspiration tests with these products to rule out the intravascular positioning of the needles. Decreasing the products' viscosity through dilution, or switching to a larger bore and shorter needle may increase the reliability of aspiration tests. Further research on the aspiration tests during filler treatment is warranted for the development of relevant guidelines.

\section{CONFLICT OF INTEREST}

No potential conflict of interest relevant to this article was reported.

\section{REFERENCES}

1. American Society for Dermatologic Surgery. Survey on dermatologic procedures: report of 2018 procedures. [serial online] 2019 Aug [cited 2020 Jan 25]; Available from: URL: https://www.asds.net/portals/0/PDF/procedures-surveyresults-presentation-2018.pdf

2. Signorini M, Liew S, Sundaram H, De Boulle KL, Goodman GJ, Monheit G, et al. Global Aesthetics Consensus: avoidance and management of complications from hyaluronic acid fillers-evidence- and opinion-based review and consensus recommendations. Plast Reconstr Surg 2016;137:961e-71e.

3. Albornoz CA, Jhawar N, Durso TA, Hazan E, Wang JV, Saedi N. Preinjection aspiration for injectable fillers in aesthetic dermatology: trust or bust? J Cosmet Dermatol 2020;19:1063-4.

4. Pierre S, Liew S, Bernardin A. Basics of dermal filler rheology. Dermatol Surg 2015;41 Suppl 1:S120-6.

5. Sundaram H, Voigts B, Beer K, Meland M. Comparison of the rheological properties of viscosity and elasticity in two categories of soft tissue fillers: calcium hydroxylapatite and hyaluronic acid. Dermatol Surg 2010;36 Suppl 3:1859-65.

6. Casabona G. Blood aspiration test for cosmetic fillers to prevent accidental intravascular injection in the face. Dermatol Surg 2015;41:841-7.

7. Carey W, Weinkle S. Retraction of the plunger on a syringe of hyaluronic acid before injection: are we safe? Dermatol Surg 2015;41 Suppl 1:S340-6.

8. Van Loghem JA, Fouché JJ, Thuis J. Sensitivity of aspiration 
as a safety test before injection of soft tissue fillers. J Cosmet Dermatol 2018;17:39-46.

9. Torbeck RL, Schwarcz R, Hazan E, Wang JV, Farberg AS, Khorasani $H$. In vitro evaluation of preinjection aspiration for hyaluronic fillers as a safety checkpoint. Dermatol Surg 2019;45:954-8.

10. Busso M, Voigts R. An investigation of changes in physical properties of injectable calcium hydroxylapatite in a carrier gel when mixed with lidocaine and with lidocaine/epinephrine. Dermatol Surg 2008;34 Suppl 1:S16-23; discussion S24.

11. de Melo F, Marijnissen-Hofsté J. Investigation of physical properties of a polycaprolactone dermal filler when mixed with lidocaine and lidocaine/epinephrine. Dermatol Ther (Heidelb) 2012;2:13.

12. Rzany B, DeLorenzi C. Understanding, avoiding, and managing severe filler complications. Plast Reconstr Surg 2015;136(5 Suppl):196S-203S.

13. Lee W, Oh W, Moon HJ, Koh IS, Yang EJ. Soft tissue filler properties can be altered by a small-diameter needle. Dermatol Surg. Forthcoming 2019. https://doi.org/10.1097/ DSS.0000000000002220 